\title{
Performance Evaluation of GaN-Based Synchronous Boost Converter under Various Output Voltage, Load Current, and Switching Frequency Operations
}

\author{
Di Han* and Bulent Sarlioglu ${ }^{\dagger}$ \\ ${ }^{*}, \dagger$ Department of Electrical and Computer Engineering, University of Wisconsin-Madison, Madison, U.S.A
}

\begin{abstract}
Gallium nitride (GaN)-based power switching devices, such as high-electron-mobility transistors (HEMT), provide significant performance improvements in terms of faster switching speed, zero reverse recovery, and lower on-state resistance compared with conventional silicon ( $\mathrm{Si}$ ) metal-oxide-semiconductor field-effect transistors (MOSFET). These benefits of GaN HEMTs further lead to low loss, high switching frequency, and high power density converters. Through simulation and experimentation, this research thoroughly contributes to the understanding of performance characterization including the efficiency, loss distribution, and thermal behavior of a $160-\mathrm{W}$ GaN-based synchronous boost converter under various output voltage, load current, and switching frequency operations, as compared with the state-of-the-art Si technology. Original suggestions on design considerations to optimize the GaN converter performance are also provided.
\end{abstract}

Key words: Gallium nitride, Semiconductor loss, Synchronous boost converter

\section{INTRODUCTION}

With the continuing trend toward higher power rating, higher efficiency, lighter weight, and smaller size power electronic converters in various applications [1]-[6], the need for better performance power switching devices has been warranted. In recent years, wide bandgap (WBG) semiconductor materials, such as silicon carbide $(\mathrm{SiC})$ and gallium nitride $(\mathrm{GaN})$ based devices have become available [7]-[14]. SiC- and GaN-based switching devices have low semiconductor loss, high switching speed, and high temperature capability because of the superior physical properties of WBG materials, such as high electric breakdown field, low intrinsic carrier concentration, and large saturated electron drift velocity. This research aims to thoroughly investigate performance characteristics including the efficiency, loss distribution, and thermal behavior of the latest GaN device in a synchronous boost converter and to

Manuscript received Mar. 1, 2015; accepted Jun. 25, 2015

Recommended for publication by Associate Editor Joung-Hu Park.

${ }^{\dagger}$ Corresponding Author: sarlioglu@wisc.edu

Tel: +1-608-262-2703, Fax: +1-608-263-3160, University of Wisconsin-Madison

*Department of Electrical and Computer Engineering, University of Wisconsin-Madison, U.S.A contribute to the optimized usage of $\mathrm{GaN}$ devices by providing original suggestions on the $\mathrm{GaN}$ converter design.

$\mathrm{SiC}$ devices have been extensively studied in the past decade because of their relatively high level of maturity [15]-[17]. In contrast, GaN devices have just started to become available to public and, hence, are less investigated in literature. In [18], a GaN high-electron-mobility transistors (HEMT) boost converter is shown to achieve $98 \%$ efficiency at 300-W output power at a switching frequency of $1 \mathrm{MHz}$. A $10-\mathrm{W}$ synchronous buck converter using GaN-on-SiC HEMTs is demonstrated in [19], achieving 95\% efficiency at $10-\mathrm{MHz}$ switching frequency and $90 \%$ efficiency at $40-\mathrm{MHz}$ switching frequency. Reference [20] presents a $3-\mathrm{kW} 400$ 800-V GaN-based boost converter that shows 99\% efficiency at $100-\mathrm{kHz}$ switching frequency. In [21], a GaN device is used in a hybrid resonant converter with $97.5 \%$ California Energy Commission weighted efficiency. Reference [22] characterizes the efficiency improvements by using GaN-based source-switched field-effect transistors (SSFET) in a PFC boost converter. However, the present research limits its focus on efficiency comparison for a few operating conditions at a fixed switching frequency. At present, studies have not evaluated the performance of GaN HEMT over a wide range of operating voltage, current, switching 
TABLE I

COMPARISON OF GAN HEMT AND SI MOSFET UNDER STUDY

\begin{tabular}{l|l|l}
\hline Part number & EPC2001 & RJK1053DPB \\
\hline Material & $\mathrm{GaN}$ & $\mathrm{Si}$ \\
\hline Voltage rating $\mathrm{V}_{\mathrm{DS}}$ & $100 \mathrm{~V}$ & $100 \mathrm{~V}$ \\
\hline Current rating $\mathrm{I}_{\mathrm{D}}($ Continuous $)$ & $25 \mathrm{~A}$ & $25 \mathrm{~A}$ \\
\hline On-state resistance $\mathrm{R}_{\mathrm{DSon}}(\mathrm{Max})$ & $7 \mathrm{~m} \Omega$ & $15 \mathrm{~m} \Omega$ \\
\hline Total gate charge $\mathrm{Q}_{\mathrm{g}}$ & $8 \mathrm{nC}$ & $43 \mathrm{nC}$ \\
\hline Gate to source charge $\mathrm{Q}_{\mathrm{gs}}$ & $2.3 \mathrm{nC}$ & $19 \mathrm{nC}$ \\
\hline Gate to drain charge $\mathrm{Q}_{\mathrm{gd}}$ & $2.2 \mathrm{nC}$ & $12.5 \mathrm{nC}$ \\
\hline Body diode reverse recovery & No & Yes \\
\hline $\begin{array}{l}\text { Source-drain forward voltage } \mathrm{V}_{\mathrm{SD}} \\
\left(\mathrm{I}_{\mathrm{D}}=-25 \mathrm{~A}, \mathrm{~T}=25^{\circ} \mathrm{C}\right)\end{array}$ & $2.3 \mathrm{~V}$ & $0.83 \mathrm{~V}$ \\
\hline $\begin{array}{l}\text { Output capacitance } \mathrm{C}_{\text {oss }}\left(\mathrm{V}_{\mathrm{DS}}=50 \mathrm{~V},\right. \\
\left.\mathrm{V}_{\mathrm{gs}}=0 \mathrm{~V}\right)\end{array}$ & $450 \mathrm{pF}$ & $210 \mathrm{pF}$ \\
\hline $\begin{array}{l}\text { Thermal resistance, junction to case } \\
\mathrm{R}_{\theta \mathrm{C} C}\end{array}$ & $2.1^{\circ} \mathrm{C} / \mathrm{W}$ & $1.92{ }^{\circ} \mathrm{C} / \mathrm{W}$ \\
\hline
\end{tabular}

frequencies.

The objective of this paper is to contribute to the analysis of important and different characteristics of GaN HEMTs in power converters, as compared to conventional Si MOSFETs, which will be achieved through quantifying the loss, efficiency, and temperature rise of a $\mathrm{GaN}$ synchronous boost converter over a wide range of operating conditions. The research results will provide pertinent and important design suggestions, as well as comprehensive and valuable firsthand data, which are critical in reducing the knowledge gap for practical engineers and decision makers.

The paper is organized as follows. In Section II, a GaN HEMT device is compared to the same rated Si MOSFET in terms of critical device parameters. A 160-W synchronous boost converter is simulated in Section III using GaN HEMTs and $\mathrm{Si}$ MOSFETs under various operating conditions. Experimental results on the GaN-based converter are presented in Section IV to validate the simulation. In addition, discussion and suggestions on the effective usage of GaN HEMTs are provided. Finally, conclusions are drawn in Section V.

\section{GAN-BASED POWER DEVICES}

Theoretically, GaN is an excellent material for making power switching devices targeting high-voltage, high-frequency, and high-temperature applications because of its large critical electric field, high electron mobility, low carrier concentration, and good thermal conductivity [9]. However, because of the lack of commercially available low-cost and high-quality GaN substrates, GaN epilayers are mainly grown on $\mathrm{Si}$ substrates and become the technical bottleneck that limits the available device type, voltage rating, and thermal conductivity. At present, the GaN-based power devices in the market are either normally-off GaN HEMT rated at $40-200 \mathrm{~V}$ or $600-650 \mathrm{~V}$ cascode switch based on series connection of normally-on GaN HEMT and $\mathrm{Si}$

\section{MOSFET.}

In this study, the GaN device chosen is a $100-\mathrm{V} 25-\mathrm{A}$ HEMT (EPC2001) from EPC. A corresponding state-of-the-art $\mathrm{Si}$ device with the same ratings is the MOSFET (RJK1053DPB) from Renesas Electronics. Although GaN HEMT is more expensive than Si MOSFET at present, the price of GaN devices is believed to gradually decrease as manufacturing techniques improve. Hence, the device costs are not taken into account in this study.

A few important characteristic parameters of the two devices are compared in Table I below. Key observations from the table are summarized as follows.

1) The GaN HEMT and Si MOSFET chosen for the study have the same voltage rating of $100 \mathrm{~V}$ and current rating of $25 \mathrm{~A}$, which guarantee a fair comparison between the GaN and Si technology.

2) The GaN HEMT has a maximum on-state resistance $R_{D S o n}$ of only $7 \mathrm{~m} \Omega$, which is less than half of the value for $\mathrm{Si}$ MOSFET $(15 \mathrm{~m} \Omega)$ and thus indicates halved conduction loss during operation.

3) The gate charge values $\left(Q_{g s}, Q_{g d}\right.$, and $\left.Q_{g}\right)$ of GaN HEMT are five to ten times smaller than those of the Si MOSFET. As a result, with the same level of gate current, the gate capacitance of a GaN HEMT will be charged within 1/5 the time needed by Si MOSFET, which further translates into the fast turn-on and turn-off of the GaN conduction channel.

4) While the body diode of $\mathrm{Si}$ MOSFET has reverse recovery effect because of the $\mathrm{p}-\mathrm{n}$ junction nature of the parasitic diode in a MOSFET, GaN HEMT has a "major carrier body diode" that features zero reverse recovery.

5) The forward voltage drop of the GaN body diode $(2.3 \mathrm{~V})$ is roughly three times that of the $\mathrm{Si}$ counterpart $(0.83 \mathrm{~V})$ and indicates the high reverse conduction loss of $\mathrm{GaN}$ HEMT, which is a direct result of the wide energy band gap of GaN material.

6) At 50-V drain-to-source voltage, output capacitance $C_{o s s}$ of GaN HEMT (450 pF) is more than twice that of $\mathrm{Si}$ MOSFET $(210 \mathrm{pF})$, which is also true for other drain-to-source voltage values. As a result, the energy stored in output capacitance of GaN HEMT during off-state is significant.

7) Thermal resistance $R_{\theta J C}$ of GaN device is slightly higher than that of $\mathrm{Si}$ MOSFET, which is mainly because thermal contact resistance formed between GaN epilayer and Si substrate on which it is grown.

To clearly understand the strengths and weaknesses of GaN HEMTs, analyses are given from the following three aspects, i.e., conduction loss $P_{c}$, switching loss $P_{s w}$, and temperature rise $\Delta T$.

\section{A. Conduction Loss}


The conduction loss of a field-effect transistor (FET) during on-state can be expressed as

$$
P_{C F}=\frac{1}{T_{s w}} \int_{t=0}^{T s w} p_{C F}(t) d t=R_{D S o n} \cdot I_{D r m s}^{2},
$$

where subscript "CF" represents "conduction of FET," $T_{s w}$ represents the switching period, and $I_{\text {Drms }}$ stands for the rms value of the drain current.

As shown in Equ. (1), with half RDSon, the conduction loss of $\mathrm{GaN}$ device will be half of that of the Si device when operated at the same drain current.

The conduction loss of the body diode can be expressed as

$$
P_{C D}=\frac{1}{T_{s w}} \int_{t=0}^{T s w} p_{C D}(t) d t \approx V_{S D} \cdot I_{F a v},
$$

where subscript "CD" represents "conduction of diode," and $I_{F a v}$ stands for the average value of the diode current.

Because $V_{S D}$ of the GaN device is three times that of the Si device, as can be expected from Equ. (2), the diode conduction loss of GaN device should also be three times higher given the same length of diode conduction period. Furthermore, the length of diode conduction period is dependent on dead-time values utilized during the converter operation. Hence, the selection of dead-time has a significant effect on diode conduction loss. Fortunately, the diode conduction in a synchronous boost converter can be eliminated by optimizing the dead-times [23].

An assumption in this study is that the technique described in [23] has been adopted for both $\mathrm{Si}$ and $\mathrm{GaN}$ based converter such that diode conduction is negligible. Hence, the total conduction loss should be

$$
P_{C}=P_{C F}+P_{C D} \approx P_{C F} \text {. }
$$

\section{B. Switching Loss}

Switching loss $P_{s w i}$ that occurred during the switching transitions can be divided into three major components as

$$
P_{s w i}=P_{v i}+P_{r r}+P_{\text {oss }} \text {, }
$$

where $P_{v i}$ represents the switching loss without considering reverse recovery and output capacitive charge, $P_{r r}$ represents the loss induced by body diode recovery, and $P_{\text {oss }}$ represents the loss induced by the energy stored in output capacitors $C_{o s s}$ of devices. These three components can be further estimated as follows:

$$
\begin{gathered}
P_{v i}=V_{o} \cdot I_{D o n} \cdot\left(t_{r i}+t_{f w}\right) / 2 \cdot f_{s w}, \\
P_{r r}=Q_{r r} \cdot V_{D S o n} \cdot f_{s w}, \\
P_{o s s}=\int_{t=0}^{V o} Q_{o s s}\left(V_{D S}\right) d V \cdot f_{s w},
\end{gathered}
$$

where $V_{o}$ is the output voltage, $t_{r i}$ and $t_{f u}$ are the current rise time and voltage fall time, respectively, $Q_{r r}$ is the reverse recovery charge, and $f_{s w}$ is the switching frequency.

As observed earlier, with five to ten times smaller gate charge $t_{r i}$ and $t_{v f}$ of GaN HEMT will be significantly smaller than that of Si MOSFET, leading to smaller $P_{v i}$. Similarly, with

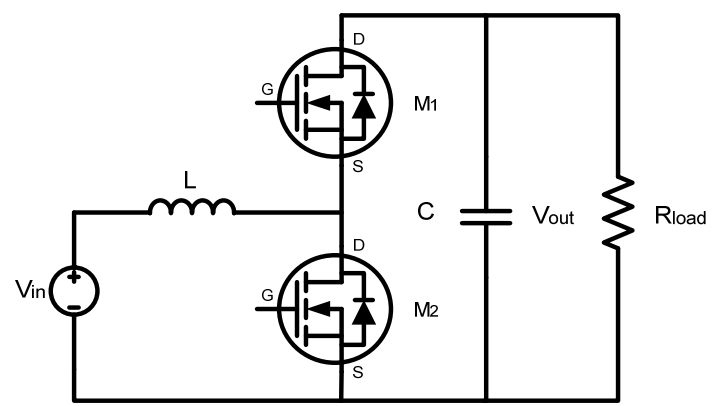

Fig. 1. Schematic of the boost converter under study.

TABLE II

SPECIFICATIONS OF THE BoOST CONVERTER UNDER STUdY

\begin{tabular}{lc}
\hline Specifications & Value \\
\hline Low side voltage $\mathrm{V}_{\text {in }}(\mathrm{V})$ & 24 \\
High side voltage $\mathrm{V}_{\text {out }}(\mathrm{V})$ & $48-80$ \\
Power rating $\mathrm{P}(\mathrm{W})$ & 160 \\
Switching frequency $\mathrm{f}(\mathrm{kHz})$ & $100-300$ \\
Chock inductor $\mathrm{L}(\mu \mathrm{H})$ & 20 \\
DC bus capacitor $\mathrm{C}(\mu \mathrm{F})$ & 60 \\
Input capacitor $\mathrm{C}_{\text {in }}(\mu \mathrm{F})$ & 10 \\
\hline
\end{tabular}

zero $Q_{r r}$, GaN device generate zero $P_{r r}$, whereas the reverse recovery loss of Si MOSFET can be prominent. However, with two times larger $\mathrm{C}_{\text {oss }}, P_{\text {oss }}$ term of the GaN device is expected to be larger than that of the Si device.

The first two terms, i.e., $P_{v i}$ and $P_{r r}$, typically dominate the third term in switching loss, and the total switching loss in $\mathrm{GaN}$ converter is expected to be smaller than that of $\mathrm{Si}$ converter.

\section{Temperature Rise}

The temperature rise from device junction to case can be simply estimated as

$$
\Delta T_{J C}=\left(P_{C}+P_{s w i}\right) R_{\theta J C} .
$$

Although thermal resistance $R_{\theta J C}$ of the $\mathrm{GaN}$ device is slightly higher than the Si device, the actual temperature rise can still be smaller in the GaN devices because of the reduced losses.

In the following sections, the overall effects of these counteracting features of GaN HEMTs will be explored as applied to a synchronous boost converter.

\section{SIMULATION OF SYNCHRONOUS BOOST CONVERTER}

The synchronous boost converter used in this case study is shown in Fig. 1. Some specifications of the converter, which is $160 \mathrm{~W}$ converter with a boost ratio of $24-80 \mathrm{~V}$, are listed in Table II. These ratings suit a typical photovoltaic application as a modular DC-DC converter in the distributed MPPT architecture.

\section{A. Simulation Methods}

The purpose of this work is to thoroughly study the 
performance of the GaN-based boost converter described above, under different operating conditions, and compare it with the corresponding Si-based converter.

To achieve this purpose, the proposed boost converter is simulated under four load currents $(1,2,3$, and $4 \mathrm{~A}$ ), four switching frequencies $(100,200,300$, and $400 \mathrm{kHz})$, and three output voltages $(48,64$, and $80 \mathrm{~V})$ for both the $\mathrm{GaN}$ HEMTs and Si MOSFETs as switching devices. Of the three variables, (i.e., load current, switching frequency, and output voltage,), only one is varied at a time, whereas the other two will be set at a default value. The default values for the three variables are $2 \mathrm{~A}, 300 \mathrm{kHz}$, and $48 \mathrm{~V}$, respectively.

The converter simulation is performed using the circuit simulation tool LTSpice. The SPICE models of the two switching devices are both from their manufacturer. Gate driver circuitry is simplified using programmable independent voltage sources in the simulation. A rise and fall time of $7 \mathrm{~ns}$ and $1.5 \mathrm{~ns}$ is used to be consistent with the performance of a commercial gate driver chip LM5113. Although the device junction temperature is not known, it is assumed to be $80^{\circ} \mathrm{C}$ in the simulation as a best estimation.

In this boost converter, instead of merely implementing the upper switch as a diode, a transistor is used complementarily with the bottom switch, i.e., works in synchronous rectifying mode. Hence, a short deadtime of only $5 \mathrm{~ns}$ is added between the complementary gate signals to prevent the shoot through problem, as well as minimize the diode conduction.

\section{B. Switching Performances}

In this part, the switching performances of the $\mathrm{GaN}$ and $\mathrm{Si}$ converters will be compared. The turn-on and turn-off waveforms of lower switch M2 is shown in Figs. 2 and 3, respectively.

As shown in Fig. 2, the voltage fall time tvf of GaN device is only $2.2 \mathrm{~ns}$, with a dv/dt of $22.7 \mathrm{kV} / \mu \mathrm{s}$. The voltage fall time of Si device is roughly $23 \mathrm{~ns}$, with a dv/dt of $2.0 \mathrm{kV} / \mu \mathrm{s}$. Similarly, the current rise time of the GaN device is significantly smaller than that of the Si device. As a result, the intersection of non-zero voltage and current of the GaN device is considerably smaller than that of $\mathrm{Si}$, indicating smaller switching loss of $\mathrm{GaN}$ during turn-on despite its larger $C_{\text {oss }}$.

As shown in Fig. 3, the switching waveforms during turn-off are very close for the GaN- and Si-based converters. Thus, the switching loss during turn-off is expected to be similar.

\section{Converter Performance under Various Loads}

In the simulation, the power consumed on each circuit component is obtained. Converter efficiency is calculated as the ration of the power absorbed on load resistance to the power supplied by the source. The losses on semiconductor devices and passive components are recorded separately. The core loss of the inductor is also accounted for by referring to

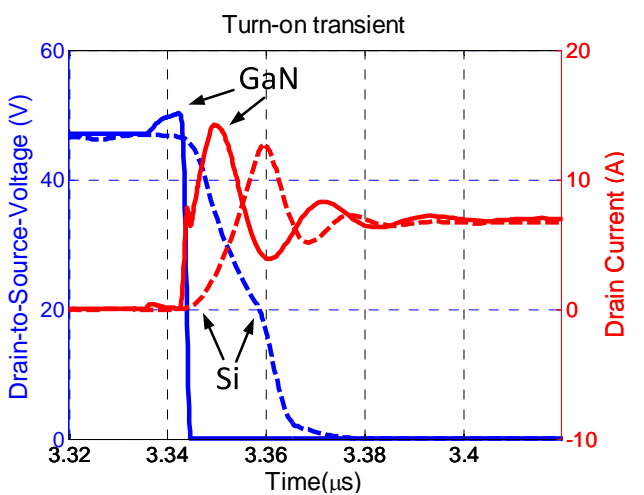

Fig. 2. Drain-to-source voltage $V_{D S}$ and drain current $I_{D}$ waveforms during $\mathrm{M}_{2}$ turn on, $48 \mathrm{~V}$ output voltage, $4 \mathrm{~A}$ load, and $300 \mathrm{kHz}$ switching frequency.

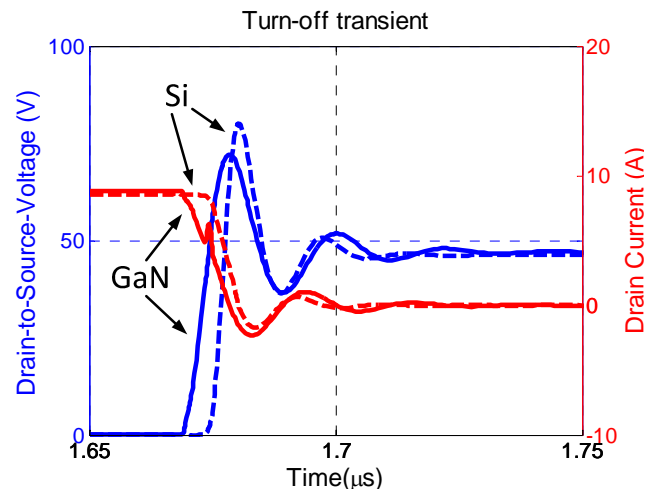

Fig. 3. Drain-to-source voltage $V_{D S}$ and drain current $I_{D}$ waveforms during $\mathrm{M}_{2}$ turn off, $48-\mathrm{V}$ output voltage, 4-A load, and $300-\mathrm{kHz}$ switching frequency.

the core material datasheet. However, the loss of gate driver is not considered because of its low value.

The converter loss and efficiency comparison under different load currents are plotted in Figs. 4 and 5, respectively.

As shown in Fig. 4, the total losses on $\mathrm{GaN}$ and $\mathrm{Si}$ converters are very similar at light loads, but a significant difference is shown at heavier loads. For example, at 1-A load current, the loss on the Si converter is higher than that of the GaN converter by only about $0.04 \mathrm{~W}$, but at 4-A load current, this difference increases to about $1.3 \mathrm{~W}$ because as the load increases, the semiconductor loss on the GaN HEMT increases by a small amount (from 0.51 to $0.83 \mathrm{~W}$ ), whereas the loss on Si MOSFET almost quadrupled (from 0.53 to 2.0 W). This observation indicates that the GaN HEMT has much smaller conduction loss than Si MOSFET, particularly at large load conditions.

The passive component loss on both converters increases dramatically with load current because of the current squared relationship. In addition, the passive component loss always dominates the total loss for 2-4-A load conditions in the GaN converter. The main sources of passive components loss are the winding loss and core loss on the choke inductor.

As shown in Fig. 5, the efficiency on the GaN converter is 


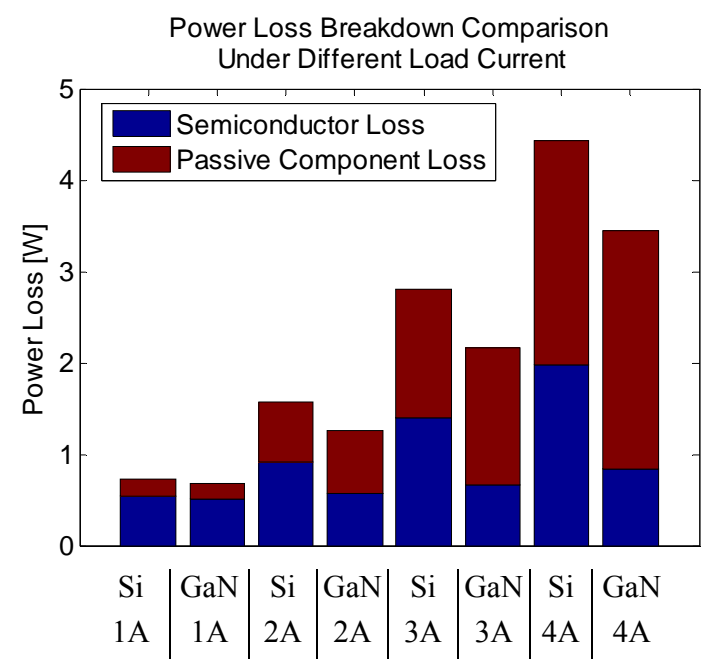

Fig. 4. Converter loss breakdown for different load current, $48-\mathrm{V}$ output voltage, and $300-\mathrm{kHz}$ switching frequency.

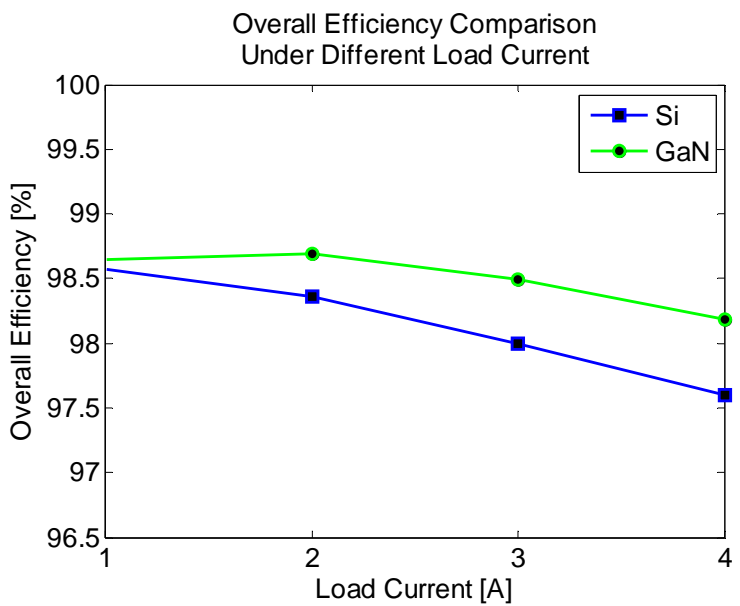

Fig. 5. Converter efficiency under different load current, $48-\mathrm{V}$ output voltage, and $300-\mathrm{kHz}$ switching frequency.

higher than its Si counterpart by $0.08 \%$ at 1 -A load and $0.59 \%$ at 4-A load. The increased efficiency difference is because of the increased loss difference explained earlier.

\section{Converter Performance under Various Switching Frequencies}

The converter loss and efficiency data under various switching frequencies are shown in Figs. 6 and 7 , respectively.

As shown in Fig. 6, as the switching frequency increases from 100 to $400 \mathrm{kHz}$, the semiconductor loss on the $\mathrm{Si}$ MOSFET increases from 0.47 to $1.15 \mathrm{~W}$, and the loss on the GaN HEMT increases from 0.27 to $0.71 \mathrm{~W}$. The loss difference between two devices also increases from 0.2 to $0.44 \mathrm{~W}$, which indicates that the GaN HEMT has better switching performance than the Si MOSFET.

The passive component loss decreases a little with the increased switching frequency because of the reduced current ripple. As a result, the semiconductor loss becomes the

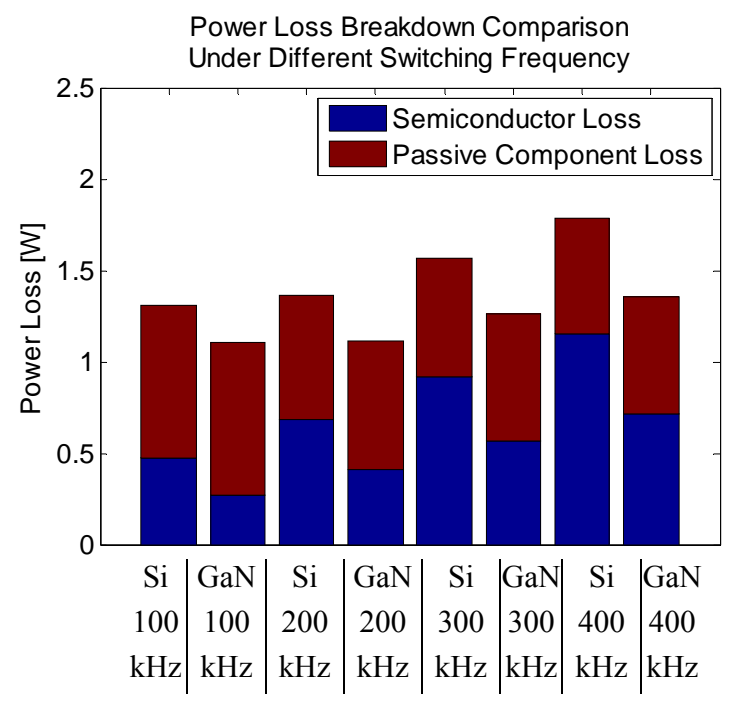

Fig. 6. Converter loss breakdown for different switching frequencies, 2-A load current, and 48-V output voltage.

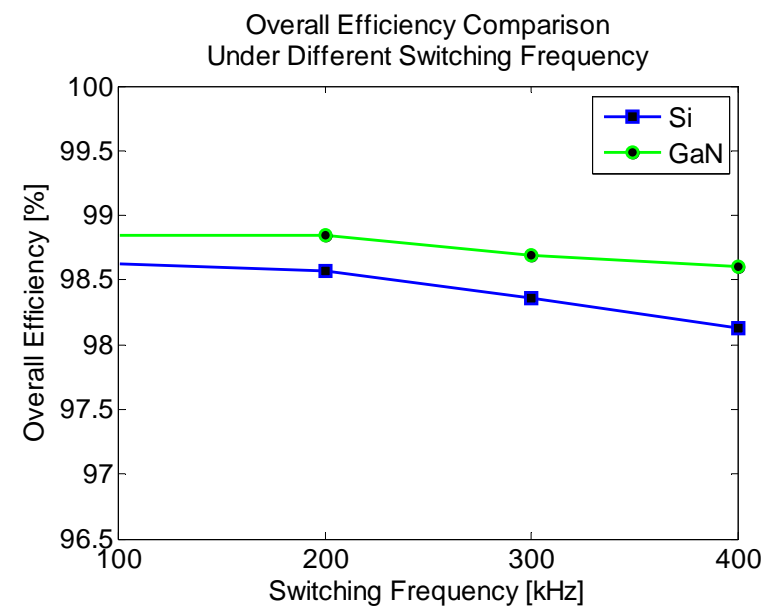

Fig. 7. Converter efficiency under different switching frequencies, 2-A load current, and 48-V output voltage.

dominant loss component in the GaN converter at the switching frequency of $400 \mathrm{kHz}$.

The corresponding efficiencies range from $98.13 \%$ to $98.63 \%$ for the Si converter and from $98.61 \%$ to $98.85 \%$ for the GaN converter.

\section{E. Converter Performance under Various Output Voltage}

The converter loss and efficiency data under various switching frequencies are shown in Figs. 8 and 9.

As shown in Fig. 8, as the output voltage increases, both semiconductor loss and passive component loss increase dramatically for the two converters. The loss on the Si MOSFETs is approximately twice the loss on GaN HEMTs for the three voltages.

The overall efficiency drops from $98.36 \%$ to $97.26 \%$ for the $\mathrm{Si}$ converter and from $98.70 \%$ to $98.03 \%$ for the $\mathrm{GaN}$ converter as the output voltage increases from 48 to $80 \mathrm{~V}$. 


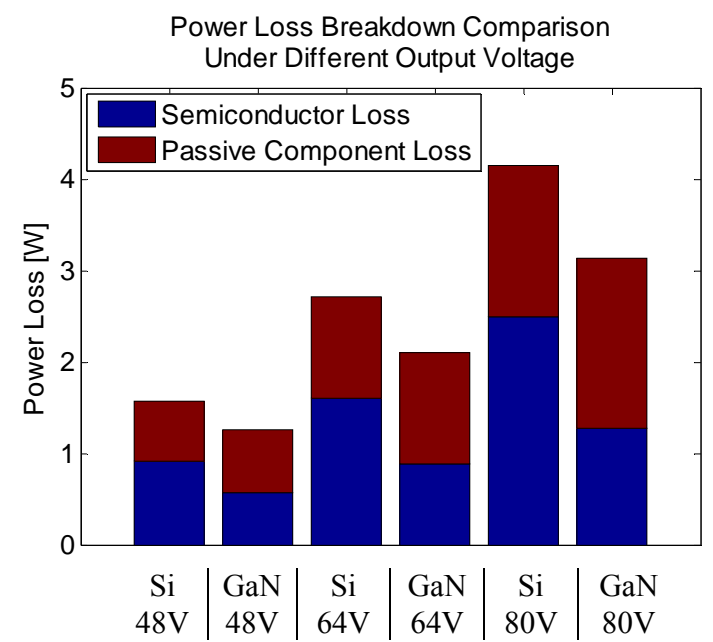

Fig. 8. Converter loss breakdown for different output voltage, 2-A load current, and 300-kHz switching frequency.

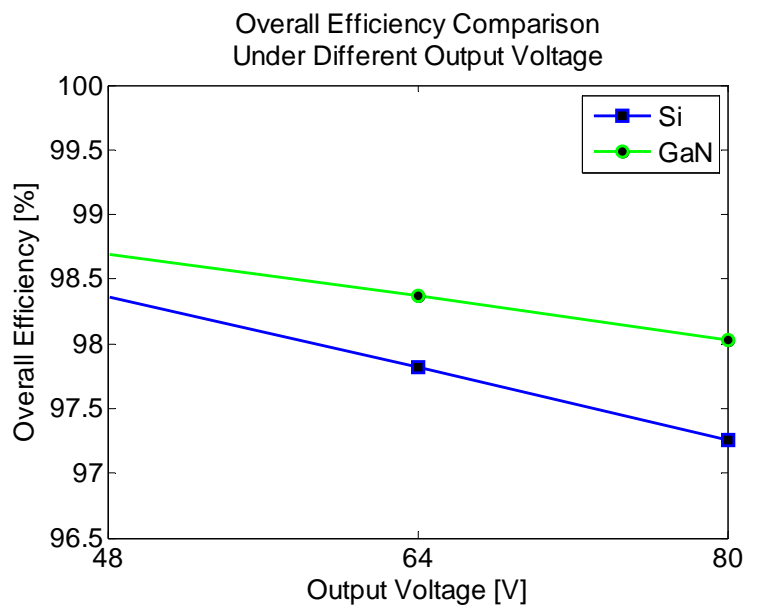

Fig. 9. Converter efficiency under different output voltage, 2-A load current, and 300-kHz switching frequency.

If comparison is made between the three variables, one can conclude that, the output voltage has the most influence on the converter loss and efficiency, whereas the switching frequency has the least effect.

\section{EXPERIMENTAL TESTS ON THE GAN-BASED SYNCHRONOUS BOOST CONVERTER}

To validate the given simulation results, a $160-\mathrm{W}$ GaN-based synchronous boost converter is built according to the specifications listed in Table II. To expedite the prototyping process, an EPC9002 demo board is utilized. The demo board comes with two EPC2001 in a phase leg configuration, a gate driver LM5113 to drive the two HEMTs, and a dead-time generating circuit. Two film capacitors are used as the input and output bus capacitors of the converter. The choke inductor is purchased from Coilcraft. Fig. 10 shows the converter prototype with critical parts labeled. Gating signals for the two HEMTs are generated using a TI DSP, which is not photographed.

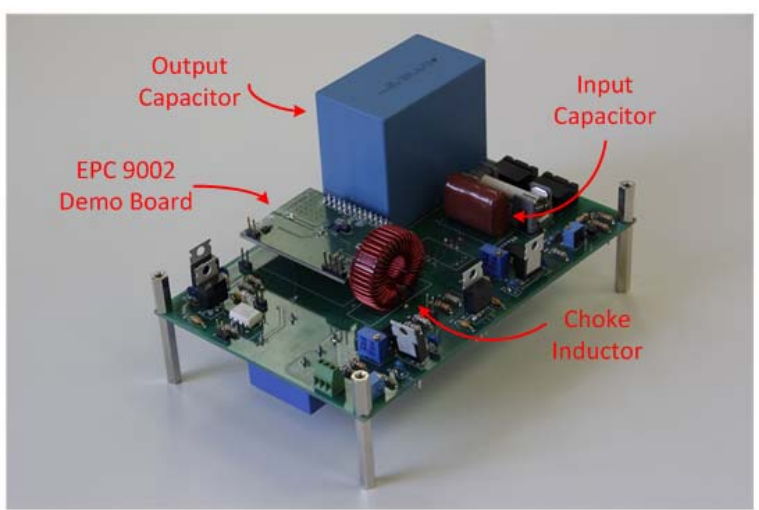

Fig. 10. Prototype GaN device based synchronous boost converter built and tested for experimental results.

TABLE III

EXPERIMENTAL TEST CASES

\begin{tabular}{ccccc}
\hline $\begin{array}{c}\text { Case } \\
\text { No. }\end{array}$ & $\begin{array}{c}\text { Input voltage } \\
\mathbf{V}_{\text {in }}(\mathbf{V})\end{array}$ & $\begin{array}{c}\text { Output } \\
\text { voltage } \\
(\mathbf{V})\end{array}$ & $\begin{array}{c}\text { Load current } \\
(\mathbf{A})\end{array}$ & $\begin{array}{c}\text { Switching } \\
\text { Frequency f } \\
(\mathbf{k H z})\end{array}$ \\
\hline 1 & 24 & 48 & 0.5 & 300 \\
2 & 24 & 48 & 1 & 300 \\
3 & 24 & 64 & 0.5 & 300 \\
4 & 24 & 80 & 0.5 & 300 \\
5 & 24 & 48 & 0.5 & 200 \\
6 & 24 & 48 & 0.5 & 400 \\
\hline
\end{tabular}

Limited by the maximum current rating of the DC power supply used in the experiment, the converter is tested under light load conditions. During the test, each of the three operating variables, i.e. load current, output voltage, and switching frequency, are varied separately while keeping the other two fixed values to evaluate the performance of the converter under various operating conditions, which is consistent with the test cases evaluated in circuit simulation, except that smaller load current values are used for the experiments. A summary of the 6 test cases are listed in Table III.

As shown in Table III, cases 1 and 2 compare two load current values while keeping the voltage and switching frequency the same. Cases 1,3 , and 4 show a variation in the output voltage, i.e., from 48 to $80 \mathrm{~V}$. Cases 1,5 , and 6 compare three different switching frequencies, i.e., 200, 300, and $400 \mathrm{kHz}$.

\section{A. Variation in Load Current}

During the experiments, four quantities, i.e., input and output voltages and currents are measured and recorded for each case. The corresponding power loss and efficiency values are obtained based on these measurements. The scope used for the measurement is WaveSurfer 104MXs-B from LeCroy with 1-GHz bandwidth and $5 \mathrm{GS} / \mathrm{s}$ sample rate. Two 20-MHz high-voltage differential probes (ADP300) are used to measure the input and output voltage. Two $100-\mathrm{MHz}$ (CP031) current probes are used to measure the input and output current. In addition, to monitor the heating of the $\mathrm{GaN}$ 


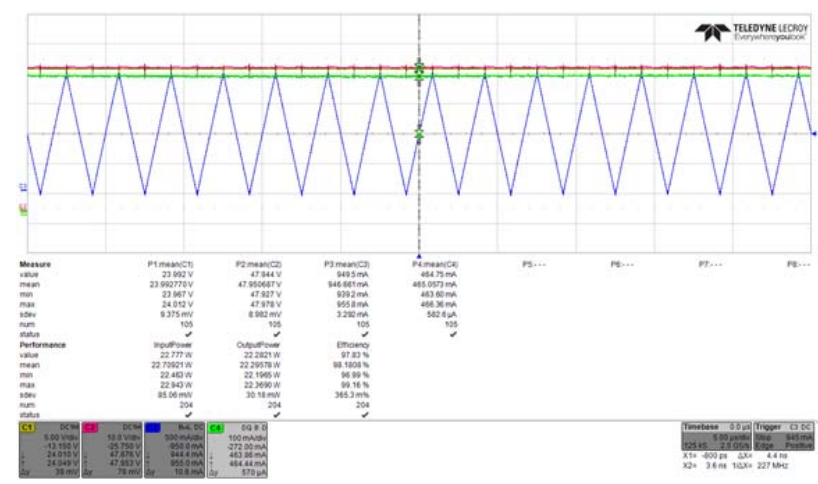

Fig. 11. (C1, yellow, $5 \mathrm{~V} /$ div) Measured waveforms for input voltage, $(\mathrm{C} 2$, red, $10 \mathrm{~V} / \mathrm{div})$ output voltage, $(\mathrm{C} 3$, blue, 500 $\mathrm{mA} /$ div) inductor current, (C4, green, $100 \mathrm{~mA} /$ div) load current, and data for test case 1 . Time scale: $5 \mu \mathrm{s} / \mathrm{div}$.

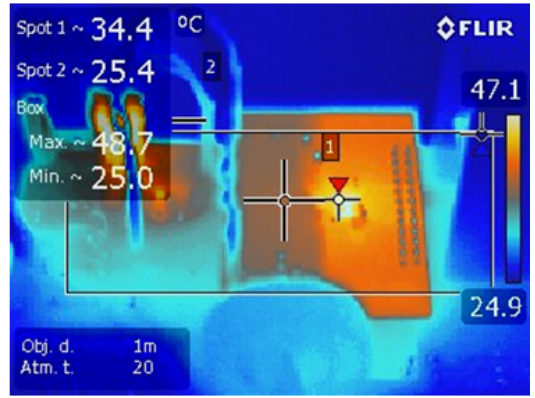

Fig. 12. Thermal image of the device on board for test case 1 .

devices, a thermal camera is also used to capture the thermal image of the board as the converter is running. To ensure the device temperature has reached a steady-state value, the converter is left running for at least $5 \mathrm{~min}$ before a thermal picture is taken.

The measured waveforms and relative data for test case 1 are shown in Fig. 11. The thermal image of case 1 is shown in Fig. 12. In Fig. 11, the important measurement data can be directly read from the scope screen. The input voltage from the DC power supply is very close to $24 \mathrm{~V}$. The output voltage is roughly $48 \mathrm{~V}$. The load current is $0.465 \mathrm{~A}$, which is slightly less than $0.5 \mathrm{~A}$. As shown, the overall converter efficiency is $98.18 \%$, and the loss is about $0.4 \mathrm{~W}$. Note that the loss measured here is only the loss on the main power circuit, and the gate driver circuit loss is not included.

In the thermal picture in Fig. 12, the square board in the middle is the demo board EPC 9002. The hot spot indicated by the red triangle is exactly where the two $\mathrm{GaN}$ devices are located. The maximum temperature value of $48.7^{\circ} \mathrm{C}$ shown in the picture corresponds to the hot spot temperature. Hence, the device case temperature has reached $48.7^{\circ} \mathrm{C}$ in this case.

The measured waveforms and thermal image for test case 2 are shown in Figs. 13 and 14, respectively. As shown in Fig. 13, the input and output voltage are 21.6 and $42.9 \mathrm{~V}$, respectively, which are slightly lower than the ideal values. The load current is also slightly less than the ideal value; the load current is $0.96 \mathrm{~A}$ instead of $1 \mathrm{~A}$ because of the limitation of the DC power supply. The converter loss in test case 2 is

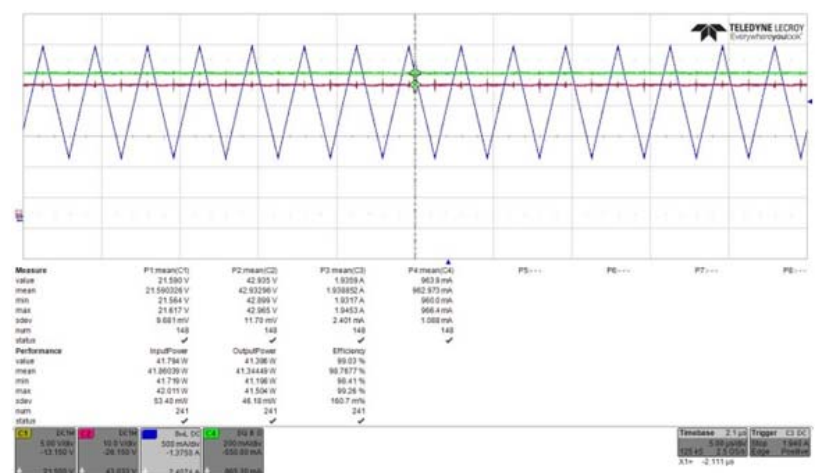

Fig. 13. (C1, yellow, $5 \mathrm{~V} /$ div) Measured waveforms for input voltage, (C2, red, $10 \mathrm{~V} / \mathrm{div})$ output voltage, (C3, blue, 500 $\mathrm{mA} /$ div) inductor current, (C4, green, $200 \mathrm{~mA} / \mathrm{div}$ ) load current, and data for test case 2 . Time scale: $5 \mu \mathrm{s} / \mathrm{div}$.

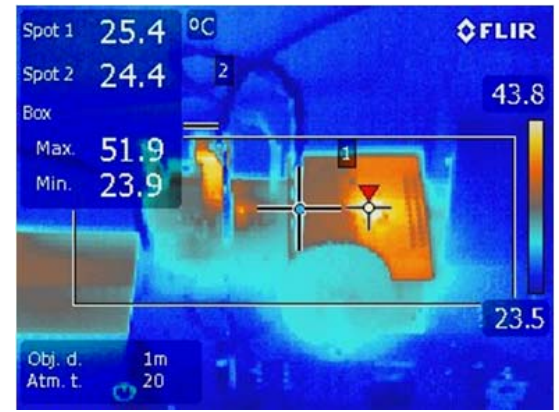

Fig. 14. Thermal image of the device on board for test case 2 .

about $0.5 \mathrm{~W}$, which corresponds to $98.77 \%$, as shown. The device case temperature increases to $51.9^{\circ} \mathrm{C}$.

Compared to case 1 , case 2 has $0.1 \mathrm{~W}$ higher losses. This is due to the higher load current, thus higher conduction loss. Despite the higher loss, the converter in case 2 has around $0.6 \%$ higher efficiency.

\section{B. Variation in Output Voltage}

To save time and space, the waveforms and thermal measurements for the remaining test cases are not shown.

For test case 3 , the input voltage is about $23.9 \mathrm{~V}$, and the output voltage is $64.1 \mathrm{~V}$. The load current is $0.523 \mathrm{~A}$. The total converter loss is roughly $1.06 \mathrm{~W}$, and efficiency is $96.95 \%$. The device case temperature has also increased to $66.8^{\circ} \mathrm{C}$ because of the voltage rise. For test case 4 , the input voltage is about $23.8 \mathrm{~V}$, and the output voltage is around 79.6 $\mathrm{V}$. The load current is $0.513 \mathrm{~A}$. The total converter loss is roughly $1.65 \mathrm{~W}$, and the corresponding efficiency is $96.12 \%$. The case temperature of the $\mathrm{GaN}$ device reaches $71.4{ }^{\circ} \mathrm{C}$ in this condition.

According to the comparison of cases 1, 3, and 4, the converter loss increases dramatically from 0.4 to $1.65 \mathrm{~W}$ as the output voltage increases from 48 to $80 \mathrm{~V}$ because of the fact that both the current stress and voltage stress on the switching device increase as the output voltage increases. Thus, both conduction and switching losses on the device increase accordingly. The converter efficiency also decreases from $98.18 \%$ to $96.12 \%$ as the output voltage increases. 


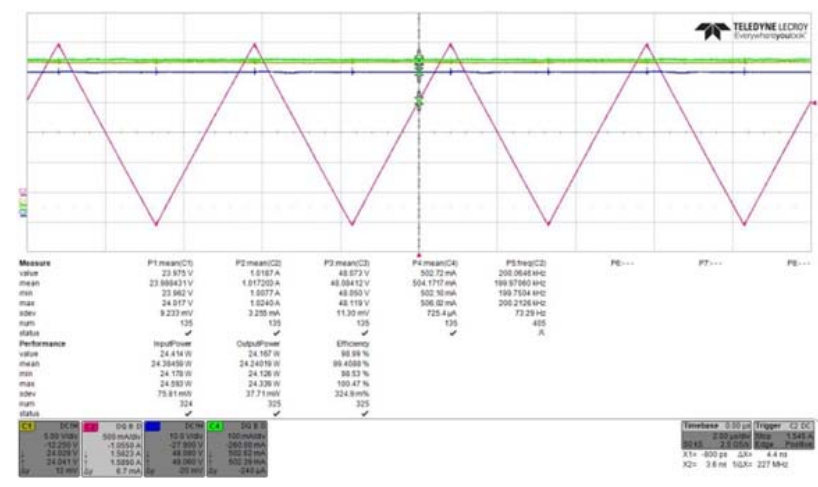

Fig. 15. (C1, yellow, $5 \mathrm{~V} /$ div) Measured waveforms for input voltage, $(\mathrm{C} 3$, blue, $10 \mathrm{~V} /$ div) output voltage, (C3, red, 500 $\mathrm{mA} /$ div) inductor current, (C4, green, $100 \mathrm{~mA} /$ div) load current, and data for test case 5 . Time scale: $2 \mu \mathrm{s} / \mathrm{div}$.

TABLE IV

EXPERIMENTAL TEST RESULTS FOR GAN CONVERTER

\begin{tabular}{|c|c|c|c|c|c|c|c|}
\hline $\begin{array}{c}\text { Case } \\
\text { No. }\end{array}$ & $\begin{array}{c}\text { Switching } \\
\text { Frequency } \\
\text { f (kHz) }\end{array}$ & $\begin{array}{c}\text { Input } \\
\text { voltage } \\
V_{\text {in }}(V)\end{array}$ & $\begin{array}{l}\text { Output } \\
\text { voltage } \\
V_{\text {out }}(V)\end{array}$ & $\begin{array}{c}\text { Load } \\
\text { current } \\
\text { (A) }\end{array}$ & $\begin{array}{c}\text { Loss } \\
P_{\text {loss }} \\
\text { (W) }\end{array}$ & $\begin{array}{c}\text { Efficie } \\
\text { ncy } \eta \\
(\%)\end{array}$ & $\begin{array}{c}\text { Device } \\
\text { Temperatu } \\
\text { re } \mathrm{T}_{\mathrm{c}}\left({ }^{\circ} \mathrm{C}\right)\end{array}$ \\
\hline 1 & 300 & 24 & 48 & 0.465 & $\overline{0.4}$ & 98.18 & 48.7 \\
\hline 2 & 300 & 21.6 & 42.9 & 0.963 & 0.5 & 98.81 & 51.0 \\
\hline 3 & 300 & 23.9 & 64.1 & 0.523 & 1.06 & 96.95 & 66.8 \\
\hline 4 & 300 & 23.8 & 79.6 & 0.513 & 1.65 & 96.12 & 71.4 \\
\hline 5 & 200 & 24 & 48.1 & 0.504 & 0.14 & 99.41 & 37.4 \\
\hline 6 & 400 & 24 & 48 & 0.504 & 0.57 & 97.70 & 55.4 \\
\hline
\end{tabular}

\section{Variation in Switching Frequency}

For test case 5 , the input voltage is $24 \mathrm{~V}$, and output voltage is $48.1 \mathrm{~V}$. The load current is $0.504 \mathrm{~A}$. In addition, the switching frequency has been reduced to $200 \mathrm{kHz}$ instead of $300 \mathrm{kHz}$, as in the previous cases. The total converter loss is about $0.14 \mathrm{~W}$, and the efficiency reaches $99.41 \%$. The case temperature of the $\mathrm{GaN}$ devices is $37.4{ }^{\circ} \mathrm{C}$ under this condition. For test case 6 , the measured input voltage for this case is $24 \mathrm{~V}$, and output voltage is about $48.1 \mathrm{~V}$. The load current is $0.504 \mathrm{~A}$. The switching frequency has been increased to $400 \mathrm{kHz}$. The total converter loss is around 1.65 $\mathrm{W}$, and the efficiency is $97.70 \%$. The corresponding GaN device case temperature for this case is $55.4{ }^{\circ} \mathrm{C}$.

According to the comparison of cases 1, 5, and 6, as the switching frequency increases from 200 to $400 \mathrm{kHz}$, the converter loss increases from 0.14 to $0.57 \mathrm{~W}$, which is a four times increase. The overall efficiency decreases from $99.41 \%$ to $97.7 \%$ because the switching loss on the GaN devices are directly related to switching frequency, and higher switching frequency yields larger loss.

Another important observation is that, with lower switching frequency, a larger current ripple on the inductor is present. In the case of $200-\mathrm{kHz}$ switching frequency, the current ripple on the inductor is about 3 A (see Fig. 15), which, because of its amplitude, causes the inductor current to reverse its direction twice every switching cycle. This current direction change actually helps the converter achieve zero voltage turn-on for both switches using a technique called zero voltage resonant-transition switching (ZVRT) [24]. This phenomenon further reduces the switching loss on top of the lower switching frequency and explains the ultra-low loss in test case 5 .

\section{Comparison between Simulation and Test Results}

All test results shown in this section have been summarized in Table IV. The observations can be concluded as follows:

1. Converter loss increases with increased load current, output voltage, and switching frequency.

2. Converter efficiency decreases with increasing output voltage and switching frequency but increases with increasing load current within the tested operating range.

3. Among load current, output voltage, and switching frequency, the output voltage variation has the largest influence on converter efficiency.

These observed trends correlate very well with the simulation results presented in Section III. Even though the measured loss and efficiency values are slightly different from the values obtained from simulation, the differences are reasonably small. For example, for test case 2, the simulated loss is $0.657 \mathrm{~W}$, and the simulated efficiency is $98.64 \%$, which is only $0.17 \%$ less than the measured value. These errors can be caused by several factors, such as inaccuracy of the device model and datasheet, unknown device junction temperatures, and errors caused by the measurement tools.

\section{DISCUSSION AND SUGGESTIONS}

\section{A. Discussion on GaN Converter Performance}

According to the results presented in the last two sections, the GaN HEMT performs better than the Si MOSFET in the converter in all operating conditions. A GaN converter has $0.08 \%-0.77 \%$ higher efficiency than a $\mathrm{Si}$ converter, depending on the operating condition, which corresponds to a maximum loss reduction of $1.23 \mathrm{~W}$ on the switching device. In addition, the maximum case temperature measured on the GaN HEMTs under all test cases is only $71.4{ }^{\circ} \mathrm{C}$, which provides abundant margin from the maximum allowable operating temperature of $125^{\circ} \mathrm{C}$. Note that the temperatures were measured when the converter was running at room temperature without any cooling methods applied. Hence, low semiconductor loss on the GaN device compensates for its relatively large thermal resistance.

Carefully examining the results further reveals two important observations. First, the major saving in a converter by using a GaN device comes from the reduction in conduction loss, particularly under large load conditions. Although the switching speed of GaN device is considerably 
faster than the $\mathrm{Si}$ device, the switching loss of the GaN converter is not significantly reduced because of the relatively large energy stored in the device output capacitor, as discussed earlier in Section II. This stored energy is lost in the conduction channel every time the device turns on and is irrelevant to the switching speed of the device. As the voltage stress on the GaN HEMT during the off-state increases, more energy will be stored in the output capacitor of the device, resulting higher switching loss.

Second, the passive component loss, which is mainly the loss on the inductor windings, presents itself as the major loss component in the GaN converter under most operating conditions, particularly under high current load. As a result, further reducing the semiconductor loss on devices will be less effective without minimizing the inductor loss, if the goal is to optimize the overall efficiency of the converter.

\section{B. Suggestion on GaN Converter Design}

To fully reap the benefits of GaN-based switching devices and to achieve ultra-high efficiency under a wide range of operating points for a GaN-based converter, the two issues mentioned above, i.e., switching loss associated with output capacitor and inductor winding loss, should be addressed properly.

To reduce the switching loss associated with output capacitor, one possible solution is to apply zero voltage switching (ZVS) technique. A preferable method is to allow the converter to operate in a synchronous conduction mode. as shown in experimental test case 5, achieving ZVRT, and thus eliminating the energy loss on output capacitors by transferring them between the upper and lower switches during each switching transition. Other ZVS techniques are also open for consideration.

To reduce the inductor winding loss, apart from optimizing the inductor design, one possible solution is to further increase the switching frequency of the GaN device, with the assumption that the switching loss mentioned above has been reduced to a reasonably small value. With increased switching frequency, the required choke inductance value will decrease, resulting in not only a smaller inductor size, but also less winding turns and smaller winding resistance.

\section{CONCLUSION}

This paper contributes to the evaluation of a $160-\mathrm{W}$ GaN-based synchronous boost converter and compares with the state-of-the-art Si technology.

First, the comparison of $\mathrm{GaN}$ and $\mathrm{Si}$ is made at the device level by analyzing two comparable devices. Strengths and weaknesses of GaN HEMTs are pointed out. Then, a simulation is performed for the GaN-based converter, as well as the Si-based converter, for a wide range of operating conditions, including various load currents, switching frequencies, and output voltages. A comparison is made between the performances of two converters in terms of efficiency and loss breakdown. Subsequently, experimental tests are performed on a GaN-based converter prototype to verify the simulation accuracy, as well as to obtain more information on the thermal aspect.

Lastly, discussions on GaN converter performances are given. The GaN converter shows $0.08 \%-0.77 \%$ higher efficiency than the $\mathrm{Si}$ converter over the whole operating range, featuring a maximum loss reduction of $1.23 \mathrm{~W}$ and a maximum temperature rise of approximately $51{ }^{\circ} \mathrm{C}$. The issues of output capacitor associated switching loss and inductor winding loss are also highlighted. Suggestions on solving the two issues of $\mathrm{GaN}$ converter are provided.

\section{REFERENCES}

[1] D. Ryu, B. Choi, S. Lee, Y. Kim, and C. Won, "Flyback inverter using voltage sensorless MPPT for photovoltaic AC modules," Journal of Power Electronics, Vol. 14, No. 6, pp. 1293-1302, Nov. 2014.

[2] C. Gu, H. Krishnamoorthy, P. Enjeti, Z. Zheng, and Y. Li, "A medium-voltage matrix converter topology for wind power conversion with medium frequency transformers," Journal of Power Electron., Vol. 14, No. 6, pp. 1166-1177, Nov. 2014

[3] A. Lopez, D. Patino, and R. Diez, "Efficiency analysis of a ladder multilevel converter with the use of the equivalent continuous model," Journal of Power Electron., Vol. 14, No. 6, pp. 1130-1138, Nov. 2014.

[4] H. Yoo, S. Sul, Y. Park, and J. Jeong, "System integration and power-flow management for a series hybrid electric vehicle using supercapacitors and batteries," IEEE Trans. Power Electron., Vol. 44, No. 1, pp. 108-114, Jan./Feb. 2008.

[5] J. Shin, H. Shin, G. Seo, J. Ha, and B. Cho, "Low-common mode voltage $\mathrm{H}$-bridge converter with additional switch legs," IEEE Trans. Power Electron., Vol. 28, No. 4, pp. 1773,1782, Apr. 2013.

[6] J. Lee, "Design and control methods of bidirectional DC-DC converter for the optimal DC-link voltage of PMSM drive," J. Electr. Eng. Tech., Vol. 9, No. 6, pp. 1944-1953, Nov. 2014.

[7] U. K. Mishra, L. Shen, T. E. Kazior, and Y.-F. Wu, "GaN-based RF power devices and amplifiers," Proc. IEEE, Vol. 96, No. 2, pp. 287-305, Feb. 2008.

[8] N. Kaminski, "State of the art and the future of wide band-gap devices," in Proc. IEEE Power Electron. Appl., pp. 1-9, Sep. 2009.

[9] J. Millan, P. Godignon, X. Perpina, A. Perez-Tomas, and J. Rebollo, "A survey of wide bandgap power semiconductor devices," IEEE Trans. Power Electron., Vol. 29, No. 5, p. 2155-2163, May 2014.

[10] D. Han, J. Noppakunkajorn, and B. Sarlioglu, "Comprehensive efficiency, weight, and volume comparison of $\mathrm{SiC}$ and Si-based bidirectional DC-DC converters for hybrid electric vehicles," IEEE Trans. Veh. Technol., Vol. 63, No. 7, pp. 3001-3010, Sep. 2014.

[11] M. Hakim, L. Tan, A. Abuelgasim, C. de-Groot, W. Redman-White, S. Hall, and P. Ashburn, "Drive current improvement in vertical MOSFETS using hydrogen anneal," in Proc. ICECE, pp. 217-220, Dec. 2012. 
[12] H. Liu, W. Hsu, C. Lee, B. Chou, Y. Liao, and M. Chiang, "Investigation of temperature-dependent characteristics of AlGaN/GaN MOS-HEMT by using hydrogen peroxide oxidation technique," IEEE Trans. Electron Devices, Vol. 61, No. 8, pp. 2760-2766, Aug. 2014.

[13] Y. Shin, "Effects of SPS mold on the properties of sintered and simulated SiC-ZrB2 composites," J. Electr. Eng. Tech., Vol. 6, No. 4, pp. 1474-1480, Nov. 2013.

[14] I. Kang, "Electrical characteristics of enhancement-mode n-channel vertical GaN MOSFETs and the effects of sidewall slope," J. Electr. Eng. Tech., Vol. 10, No. 3, pp. 1131-1137, May 2015.

[15] A. Elasser and T. P. Chow, "Silicon carbide benefits and advantages for power electronics circuits and systems," Proc. IEEE, Vol. 90, No. 6, pp. 969- 986, Jun. 2002.

[16] B. Ozpineci and L. M. Tolbert, "Characterization of SiC Schottky diodes at different temperatures," IEEE Power Electron. Lett., Vol. 1, No. 2, pp. 54-57, Jun. 2003.

[17] J. Biela, M. Schweizer, S. Waffler, and J. W. Kolar, "SiC vs. $\mathrm{Si}$ - evaluation of potentials for performance improvement of inverter and DC-DC converter systems by $\mathrm{SiC}$ power semiconductors," IEEE Trans. Ind. Electron., Vol. 58, No. 7, pp. 2872-2882, Jul. 2011.

[18] Y. Wu, M. Jacob-Mitos, M. L. Moore, and S. Heikman, “A 97.8\% efficient GaN HEMT boost converter with 300-W output power at $1 \mathrm{MHz}$," IEEE Electron Device Lett., Vol. 29, No. 8, pp. 824-826, Aug. 2008.

[19] M. Rodriguez, Y. Zhang, and D. Maksimovic, "High-frequency PWM buck converters using GaN-on-SiC HEMTs," IEEE Trans. Power Electron., Vol. 29, No. 5, pp. 2462-2473, May 2014.

[20] Y. Wu, J. Gritters, L. Shen, R. P. Smith, and B. Swenson, "kV-class GaN-on-Si HEMTs enabling 99\% efficiency converter at $800 \mathrm{~V}$ and $100 \mathrm{kHz}$," IEEE Trans. Power Electron., Vol. 29, No. 6, pp. 2634-2637, Jun. 2014.

[21] T. LaBella and J.-S. J. Lai, "A hybrid resonant converter utilizing a bidirectional $\mathrm{GaN}$ AC switch for high-efficiency PV applications," IEEE Trans. Ind. Appl., Vol. 50, No. 5, pp. 3468-3475, Sep./Oct. 2014.

[22] J. Yang, "Efficiency improvement with GaN-based SSFET as synchronous rectifier in PFC boost converter," in Proc. PCIM Europe, pp. 1-6, May 2014.

[23] D. Han and B. Sarlioglu, "Dead-time effect on GaN-based synchronous boost converter and analytical model for optimal dead-time selection," IEEE Trans. Power Electron., to be published.

[24] C. P. Henze, H. C. Martin, and D. W. Parsley, "Zero-voltage switching in high frequency power converters using pulse width modulation," in Proc. Appl. Power Electron. Conf., pp. 33-40, 1988.

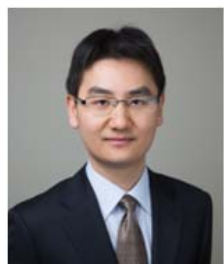

Di Han received his B. S. degree in Electrical Engineering from Huazhong University of Science and Technology, Wuhan, China, in 2011. He is currently working toward the Ph.D. degree in Electrical Engineering at the University of Wisconsin-Madison, Madison, WI. He is a Research Assistant at Wisconsin Electric Machines and Power Electronics Consortium (WEMPEC). His research interests include wide-bandgap device-based power converter design and implementation.

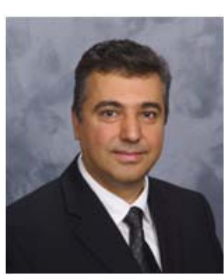

Bulent Sarlioglu received his B.S. degree from Istanbul Technical University, Istanbul, Turkey, in 1990, his M.S. degree from the University of Missouri, Columbia, MO, in 1992, and his Ph.D. degree from the University of Wisconsin-Madison, Madison, WI, in 1999, all in electrical engineering. Since 2011, he has been an Assistant Professor at the University of Wisconsin-Madison and the Associate Director of the Wisconsin Electric Machines and Power Electronics Consortium (WEMPEC). From 2000 to 2011, he worked at the aerospace division of Honeywell International Inc., Torrance, California, as a Staff Systems Engineer. He received the Outstanding Engineer Award from Honeywell in 2011. His expertise includes electrical machines, drives, and power electronics and he is the inventor or co-inventor of 16 US patents, as well as many international patents. 